\title{
BMJ Open Impact of caesarean section on breastfeeding indicators: within-country and meta-analyses of nationally representative data from 33 countries in sub-Saharan Africa
}

\author{
Engida Yisma, ${ }^{\oplus 1,2}$ Ben W Mol, ${ }^{3,4}$ John W Lynch, ${ }^{1,3,5}$ Lisa G Smithers ${ }^{1,3}$
}

To cite: Yisma E, Mol BW, Lynch JW, et al. Impact of caesarean section on breastfeeding indicators: withincountry and meta-analyses of nationally representative data from 33 countries in sub-Saharan Africa. BMJ Open 2019;9:e027497. doi:10.1136/ bmjopen-2018-027497

- Prepublication history and additional material for this paper are available online. To view these files, please visit the journal online (http://dx.doi org/10.1136/bmjopen-2018027497).

Received 25 0ctober 2018 Revised 15 July 2019 Accepted 17 July 2019
Check for updates

(C) Author(s) (or their employer(s)) 2019. Re-use permitted under CC BY-NC. No commercial re-use. See rights and permissions. Published by BMJ.

For numbered affiliations see end of article.

Correspondence to

Engida Yisma;

engida.derbie@adelaide.edu.au

\section{ABSTRACT}

Objective To examine the impact of caesarean section on breastfeeding indicators-early initiation of breastfeeding, exclusive breastfeeding under 6 months and children ever breastfed (at least once) - in sub-Saharan Africa.

Design Secondary analysis of Demographic and Health Surveys (DHS).

Setting Thirty-three low-income and middle-income countries with a survey conducted between 2010 and 2017/2018.

Participants Women aged 15-49 years with a singleton live last birth during the 2 years preceding the survey. Main outcome measures We analysed the DHS data to examine the impact of caesarean section on breastfeeding indicators using the modified Poisson regression models for each country adjusted for potential confounders. For each breastfeeding indicator, the within-country adjusted prevalence ratios (aPR) were pooled in random-effects meta-analysis.

Results The within-country analyses showed, compared with vaginal birth, caesarean section was associated with aPR for early initiation of breastfeeding that ranged from 0.24 (95\% Cl 0.17 to 0.33 ) in Tanzania to 0.89 (95\% Cl 0.78 to 1.00$)$ in South Africa. The aPR for exclusive breastfeeding under 6 months ranged from $0.58(95 \% \mathrm{Cl} 0.34$ to 0.98$)$ in Angola to $1.93(95 \% \mathrm{Cl} 0.46$ to 8.10$)$ in Cote d'Ivoire, while the aPR for children ever breastfed ranged from 0.91 (95\% Cl 0.82 to 1.02$)$ in Gabon to 1.02 (95\% Cl 0.99 to 1.04$)$ in Gambia. The meta-analysis showed caesarean section was associated with a $46 \%$ lower prevalence of early initiation of breastfeeding (pooled aPR, 0.54 ( $95 \% \mathrm{Cl} 0.48$ to 0.60$)$ ). However, meta-analysis indicated little association with exclusive breastfeeding under 6 months (pooled aPR, 0.94 (95\% Cl 0.88 to 1.01)) and children ever breastfed (pooled aPR, 0.98 (95\% Cl 0.98 to 0.99)) among caesarean versus vaginally born children.

Conclusions Caesarean section had a negative influence on early initiation of breastfeeding but showed little difference in exclusive breastfeeding under 6 months and children ever breastfed in sub-Saharan Africa.

\section{INTRODUCTION}

Breastfeeding provides protection against infection, prevents neonatal death and
Strengths and limitations of this study

- This study used nationally representative Demographic and Health Surveys (DHS) data on a large number of countries ( $n=33$ countries) over a long time period (2010-2017/2018).

- We performed analyses adjusted for potential confounders for each of the 33 countries in sub-Saharan Africa to examine the impact of caesarean section on breastfeeding indicators, and this helped us understand how the estimates (adjusted prevalence ratios) differ across countries.

In addition to the within-country adjusted analyses, we conducted random-effects meta-analysis to summarise the available evidence regarding the estimate of the impact of caesarean section on breastfeeding indicators in sub-Saharan Africa.

- DHS data do not distinguish whether the caesarean section was medically indicated or not.

improves childhood nutritional status. ${ }^{1} 2$ Moreover, breastfeeding has other numerous benefits for newborns, including reduction in risk of diarrhoea and respiratory tract infections, otitis media, asthma and allergies. ${ }^{13-7}$ Breastfeeding has also been shown to reduce risks of type 2 diabetes, ${ }^{18}$ breast and ovarian cancer for mothers. ${ }^{19}$ The World Health Organization (WHO) recommends mothers initiate breastfeeding within 1 hour of birth and exclusive breastfeeding under 6 months of life, with continued breastfeeding together with complementary feeding for 2 years to enhance growth, development and health of the child. ${ }^{1011}$ However, only $37 \%$ of infants younger than 6 months are exclusively breastfed in low-income and middle-income countries, ${ }^{1}$ suggesting the need for interventions to increase uptake and duration of breastfeeding.

Obstetrical interventions during labour and childbirth, such as caesarean section, 
influence women's breastfeeding practices and are among the causes for concern, given the rising caesarean section rates worldwide. The breastfeeding experiences of women who underwent caesarean section can be influenced by several factors, including mothers' health and emotional reactions to the surgery as well as infant health and behaviour. For instance, women's restricted mobility in the early days after caesarean birth may hinder efforts to provide basic infant care, including breastfeeding. ${ }^{12}$ As the postoperative pain may be severe, particularly in the first 24 hours, it affects the breastfeeding experience of women. ${ }^{13} 14$ Likewise, due to the potential for physical separation of the mother and infant, given the higher risk of infant admission to neonatal intensive care unit as a consequence of respiratory disorders, there might be a lesser likelihood of timely initiation of breastfeeding. ${ }^{15}$

On the other hand, it is hypothesised that the hormonal pathway that stimulates 'lactogenesis' may be disturbed by caesarean section due to maternal stress or decreased oxytocin secretion, and this, in turn, may delay milk production. ${ }^{16-18}$ As planned caesarean births are usually performed prior to the onset of labour, there is a possibility that decreased breastfeeding initiation may be attributed to these physiological reasons.

Previous evidence suggested that caesarean birth was associated with lower prevalence of early initiation of breastfeeding among mothers. For instance, in a study conducted in Canada, it was demonstrated that fewer women who had planned caesarean birth reported the practice of early initiation of breastfeeding when compared with women who did not have planned caesarean birth or had vaginal birth. ${ }^{19}$ Similarly, in a systematic review and meta-analysis involving 53 studies from 33 low-income, middle-income and high-income countries with no country from Africa, it was found that early initiation of breastfeeding was lower among infants delivered by caesarean section (pooled OR, $0.57 ; 95 \%$ CI 0.50 to 0.64 ) compared with infants born vaginally. ${ }^{20}$

Currently, much of the available evidence regarding the impact of caesarean section on breastfeeding is generated from high-income countries. In low-income and middle-income countries, even though the caesarean section rate is increasing, there is substantial inequalities which may suggest inadequate access among the poorest women and overuse of caesarean section for non-medical indications among the richest population subgroups. ${ }^{21}$ Moreover, unequal access to caesarean section due to deficiencies in transport, surgical facilities and shortage of skilled birth attendants will result in delay in accessing emergency caesarean section, which is usually accessible at specialised health facilities, and this may lead to negative outcomes. ${ }^{22-24}$ For example, breastfeeding after emergency caesarean section performed due to complicated labour may be more stressful for both mother and baby. However, there is limited insight regarding the impact of caesarean section on breastfeeding indicators-early initiation of breastfeeding (within the first hour), exclusive breastfeeding under 6 months and children ever breastfed (at least once)—in low-income and middle-income countries in sub-Saharan Africa. The purpose of this study was to examine the impact of caesarean section on breastfeeding indicators in 33 countries in sub-Saharan Africa and to summarise the findings in a random-effects meta-analysis by combining the effect estimates analysed individually to provide a consolidated effect estimate of the impact of caesarean section on breastfeeding indicators in sub-Saharan Africa.

\section{METHODS}

\section{Data sources}

We obtained data from most recent Demographic and Health Surveys (DHS) conducted in 33 sub-Saharan African countries from 2010 to 2017/2018. These countries were selected based on the availability of the most recent standard DHS data in each nation. We restricted our analysis to sub-Saharan Africa to avoid incomparability issues and the time period (2010-2017/2018) was selected to insure enough coverage of a full range of contemporaneous events in DHS within each country (eg, increase in caesarean section rates and changes in breastfeeding practices).

The DHS are widely available high-quality data source in low-income and middle-income countries and are comparable for studies across nations. DHS uses a standardised methodology and identical core questionnaire to collect nationally representative information about sociodemographic characteristics and health indicators such as maternal and child health, nutrition, HIV/ AIDS, malaria and family planning. The details about the methodology and standards for protecting the privacy of study participants in all DHS can be accessed from the DHS Program (https://dhsprogram.com/What-We-Do/ methodology.cfm). The DHS Program produces the final edited data files and make freely available to data users worldwide. The DHS Country Report, which includes the comprehensive survey results and country survey specificities (ie, sample design, non-response rate, estimates of sampling errors, data quality tables) for each country can also be accessed online (https://dhsprogram.com/publications/publications-by-type.cfm).

\section{Exposure}

The DHS questionnaire asks women about pregnancy, antenatal care and methods of delivery, including caesarean section for the most recent birth in the 2 years before the survey. The self-reported data on caesarean section rates collected for DHS, compared with facility-based records of caesarean sections, are found to be reliable in developing countries. ${ }^{25}$ In the current study, the exposure group comprised singleton last born children delivered by caesarean section while the unexposed group comprised children born vaginally in the 2 years before the survey.

\section{Outcome}

Respondents were asked a number of questions regarding breastfeeding practices, the length of breastfeeding, 
about children's consumption of liquids and solid food and micronutrient supplementation. Breastfeeding questions included whether the child was ever breastfed; how long after birth before the newborn was put to the breast; whether the baby was given anything to drink or eat other than breast milk; the type of drink given to the child and whether the child was still breastfeeding. Based on this information, three breastfeeding indicator variablesearly initiation of breastfeeding, exclusive breastfeeding under 6 months and children ever breastfed-were computed and used as an outcome of interest for this study. According to the WHO definitions, ${ }^{11}$ 'early initiation of breastfeeding' is defined as being put to the breast within an hour of birth. 'Exclusive breastfeeding under 6 months' is consuming only breastmilk (no other fluids or foods) from 0 to 5 months. 'Children ever breastfed' is the proportion of children born in the last 24 months who were ever breastfed (at least once).

\section{Confounding}

The following potential confounders were identified based on a priori subject matter and expert knowledge. They included pregnancy planning, birth weight, region of residence, sex of child, mother's age at birth (in years), mother's education, birth order, number of antenatal visits, maternal tobacco use, place of delivery, household wealth quintile, mother's occupation, distance to health facility and urban/rural residence. Mother's age at birth was calculated as a difference (in years) between infant's date of birth and mother's date of birth. DHS computes the wealth index for each survey based on household assets using principal components analyses ${ }^{26}$ and categorises households into wealth quintiles. These asset-based measures represent the wealth distribution relative to other households within each country. They are widely used and are consistent with comparisons to household expenditures and the measurement of inequalities in child mortality, education and healthcare use in low-income and middle-income countries. ${ }^{27}$ The detail description of the variables included in this study along with Directed Acyclic Graph (DAG) are presented in online web appendices $1-5$.

\section{Statistical analysis}

All analyses were weighted to be nationally representative and the analyses involved two phases. First, the modified Poisson regression models (using generalised linear model with a log link and a Poisson distribution in STATA ${ }^{28}$ ) was used for each country to calculate unadjusted and adjusted prevalence ratios (aPR) and their 95\% CIs for each breastfeeding indicator (early initiation of breastfeeding, exclusive breastfeeding under 6 months and children ever breastfed) associated with individual-level caesarean delivery versus vaginal birth. The formula for the modified Poisson regression is given by $\mathrm{Zou}^{29}$ :

$$
\log \left[\pi\left(x_{i}\right)\right]=\alpha+\beta x_{i}
$$

$$
l(\alpha, \beta)=C \cdot \sum_{i=1}^{n}\left[y_{i}\left(\alpha+\beta x_{i}\right)-\exp \left(\alpha+\beta x_{i}\right)\right]
$$

Second, meta-analyses were done to obtain pooled aPR of these associations for each breastfeeding indicator. To account for between-country variation in effect estimates, we conducted random-effects meta-analysis using inverse variance weighting using 'metan' command in STATA. All the 33 countries data analysed individually were included in the meta-analyses of the effect of caesarean section on early initiation of breastfeeding and children ever breastfed. However, for exclusive breastfeeding under 6 months, data from Chad were unable to be included because of small sample with almost no exclusive breastfeeding under 6 months and the model could not coverage. We used the $\mathrm{I}^{2}$ to measure statistical heterogeneity and the possible sources of heterogeneity were explored using a post hoc subgroup analyses based on the following subgroups: (1) categorising the countries by region-East Africa, Southern Africa, West Africa and Central Africa; (2) by rate of caesarean section categories-low $(<5 \%)$, medium $(5 \%-15 \%)$ and high $(>15 \%)$ and (3) by prevalence of early initiation of breastfeeding categories- $\leq 50 \%$ and $>50 \%$. The subcategories for geographic regions are according to United Nations geoscheme while the subcategories for caesarean section rates and prevalence of early initiation of breastfeeding were decided based on a previous study $^{30}$ and expert opinion, respectively. All analyses in this study were conducted using STATA/SE V.15.1 (Stata Corporation).

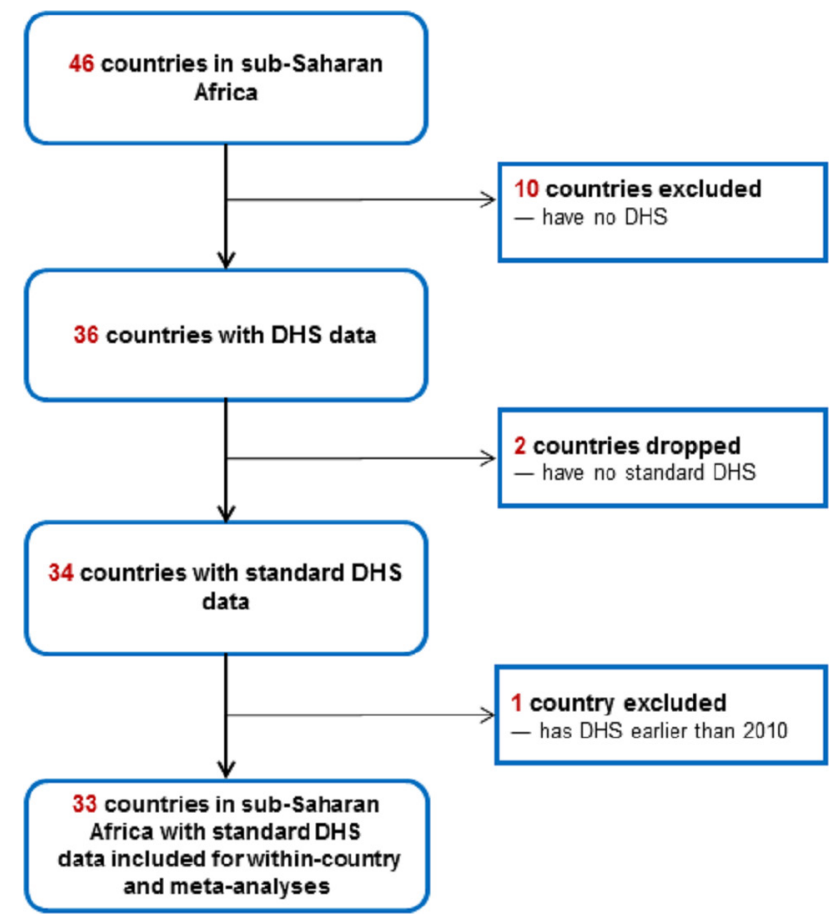

Figure 1 Flow scheme for country selection based on inclusion and exclusion criteria. DHS, Demographic and Health Surveys. 
Table 1 Among last-born children who were born in the last 2 years before the survey, percentage of live singleton births delivered by caesarean section, prevalence of early initiation of breastfeeding, prevalence of exclusive breastfeeding under 6 months and prevalence of children ever breastfed, 33 sub-Saharan African countries (2010-2017/2018)

\begin{tabular}{|c|c|c|c|c|c|}
\hline Country & Year of DHS & $\begin{array}{l}\text { Caesarean } \\
\text { section rate } \\
(\%)\end{array}$ & $\begin{array}{l}\text { Prevalence of early } \\
\text { initiation of BF } \\
(\%)\end{array}$ & $\begin{array}{l}\text { Prevalence of } \\
\text { exclusive BF } \\
\text { under } 6 \text { months } \\
\text { (\%) }\end{array}$ & $\begin{array}{l}\text { Prevalence of } \\
\text { children ever } \\
\text { breastfed } \\
(\%)\end{array}$ \\
\hline Ethiopia & 2016 & 2.6 & 73.5 & 57.8 & 96.9 \\
\hline Namibia & 2013 & 15.6 & 71.5 & 48.7 & 95.8 \\
\hline Burkina Faso & 2010 & 2.0 & 42.3 & 24.7 & 99.2 \\
\hline Burundi & 2016-2017 & 5.3 & 85.4 & 83.6 & 99.0 \\
\hline Togo & 2013-2014 & 7.1 & 60.8 & 57.1 & 98.1 \\
\hline Benin & 2017-2018 & 4.9 & 54.3 & 41.5 & 96.7 \\
\hline Cameroon & 2011 & 4.7 & 39.8 & 20.2 & 97.4 \\
\hline Comoros & 2012 & 11.4 & 33.8 & 12.5 & 93.1 \\
\hline Congo Bra & 2011-2012 & 6.6 & 23.5 & 20.6 & 94.8 \\
\hline Congo DR & 2013-2014 & 5.1 & 52.2 & 47.7 & 98.2 \\
\hline Cote d'Ivoire & 2011-2012 & 2.9 & 31.0 & 12.4 & 96.8 \\
\hline Gabon & 2012 & 10.1 & 32.6 & 6.1 & 89.9 \\
\hline Senegal & 2010-2011 & 4.8 & 48.3 & 39.2 & 97.8 \\
\hline Gambia & 2013 & 1.9 & 51.7 & 46.8 & 98.8 \\
\hline Ghana & 2014 & 12.0 & 55.6 & 52.7 & 98.4 \\
\hline Guinea & 2012 & 3.0 & 16.4 & 20.7 & 98.1 \\
\hline Liberia & 2013 & 4.1 & 61.6 & 55.8 & 98.4 \\
\hline Mali & 2012-2013 & 2.9 & 57.9 & 33.8 & 97.3 \\
\hline Mozambique & 2011 & 3.9 & 76.8 & 41.3 & 97.4 \\
\hline Niger & 2012 & 1.2 & 53.2 & 23.3 & 98.9 \\
\hline Nigeria & 2013 & 2.1 & 33.3 & 17.5 & 97.9 \\
\hline Rwanda & 2014-2015 & 13.0 & 80.8 & 88.0 & 98.8 \\
\hline Sierra Leone & 2013 & 3.8 & 54.4 & 32.5 & 97.2 \\
\hline Zambia & 2014-2015 & 4.5 & 65.9 & 73.0 & 97.8 \\
\hline Chad & 2014-2015 & 1.5 & 23.0 & 0.3 & 98.1 \\
\hline Angola & 2015-2016 & 3.9 & 48.4 & 37.5 & 95.0 \\
\hline Tanzania & 2015-2016 & 6.3 & 51.5 & 59.2 & 98.4 \\
\hline Zimbabwe & 2015 & 5.7 & 58.0 & 47.3 & 98.4 \\
\hline Malawi & 2015-2016 & 6.4 & 76.7 & 61.2 & 97.9 \\
\hline Lesotho & 2014 & 9.9 & 65.3 & 66.9 & 95.4 \\
\hline Kenya & 2014 & 8.0 & 62.3 & 61.9 & 98.8 \\
\hline Uganda & 2016 & 7.2 & 66.2 & 65.6 & 97.6 \\
\hline South Africa & 2016 & 24.3 & 67.6 & 32.2 & 84.4 \\
\hline
\end{tabular}

BF, breastfeeding; Congo Bra, Congo-Brazzaville; Congo DR, Democratic Republic of the Congo; DHS, Demographic and Health Surveys.

\section{Patient and public involvement}

No patients were involved in setting the research question or the outcome measures nor were they involved in the design and implementation of the study. No patients were asked to advise on interpretation or writing up of results. There are no plans to disseminate the results of the research to study participants or the relevant patient community.

\section{RESULTS}

The preparation of a DAG a priori helped identify the minimum set of variables needed to reduce confounding in the association between the exposure (caesarean section) and the outcomes (breastfeeding indicators). The DAG is shown in online supplementary appendix 1 .

Data were eligible for inclusion in this study if they were from a sub-Saharan Africa and involved standardised DHS 
Table 2 Crude and multivariable-adjusted prevalence ratios for early initiation of breastfeeding associated with caesarean versus vaginal births

\begin{tabular}{|c|c|c|c|c|}
\hline Country & Year of DHS & Sample size & $\begin{array}{l}\text { Unadjusted PR } \\
(95 \% \mathrm{Cl})\end{array}$ & $\begin{array}{l}\text { Adjusted PR* } \\
(95 \% \mathrm{Cl})\end{array}$ \\
\hline Ethiopia & 2016 & 4021 & 0.50 (0.35 to 0.71$)$ & 0.46 (0.32 to 0.66$)$ \\
\hline Namibia & 2013 & 2021 & 0.71 (0.62 to 0.81$)$ & 0.71 (0.62 to 0.80$)$ \\
\hline Burkina Faso & 2010 & 5745 & 0.90 (0.68 to 1.18$)$ & 0.77 (0.60 to 1.00$)$ \\
\hline Burundi & $2016-2017$ & 5182 & $0.40(0.34$ to 0.48$)$ & 0.40 (0.33 to 0.47$)$ \\
\hline Togo & 2013-2014 & 2707 & 0.60 (0.48 to 0.75$)$ & 0.55 (0.45 to 0.68$)$ \\
\hline Benin & 2017-2018 & 5337 & 0.46 (0.37 to 0.58$)$ & 0.47 (0.38 to 0.59$)$ \\
\hline Cameroon & 2011 & 4604 & 0.86 (0.68 to 1.09$)$ & 0.82 (0.65 to 1.04$)$ \\
\hline Comoros & 2012 & 1228 & 0.50 (0.31 to 0.81$)$ & 0.52 (0.33 to 0.83 ) \\
\hline Congo Bra & 2011-2012 & 3754 & 0.42 (0.22 to 0.82$)$ & 0.44 (0.23 to 0.85$)$ \\
\hline Congo DR & 2013-2014 & 7189 & 0.47 (0.36 to 0.60$)$ & 0.44 (0.34 to 0.57$)$ \\
\hline Cote d'Ivoire & 2011-2012 & 3037 & 0.44 (0.24 to 0.81$)$ & 0.48 (0.26 to 0.90$)$ \\
\hline Gabon & 2012 & 2452 & $0.27(0.14$ to 0.50$)$ & 0.29 (0.15 to 0.56$)$ \\
\hline Senegal & 2010-2011 & 4809 & 0.59 (0.43 to 0.81$)$ & 0.57 (0.42 to 0.78$)$ \\
\hline Gambia & 2013 & 3429 & 0.69 (0.43 to 1.11$)$ & 0.77 (0.47 to 1.25$)$ \\
\hline Ghana & 2014 & 2281 & 0.47 (0.36 to 0.60$)$ & 0.46 (0.35 to 0.59$)$ \\
\hline Guinea & 2012 & 2748 & $0.49(0.16$ to 1.50$)$ & 0.47 (0.15 to 1.46$)$ \\
\hline Liberia & 2013 & 3001 & $0.43(0.28$ to 0.65$)$ & 0.45 (0.30 to 0.69$)$ \\
\hline Mali & 2012-2013 & 3884 & 0.64 (0.50 to 0.82$)$ & 0.60 (0.47 to 0.77$)$ \\
\hline Mozambique & 2011 & 4519 & 0.80 (0.70 to 0.91$)$ & 0.79 (0.70 to 0.90$)$ \\
\hline Niger & 2012 & 4668 & 0.75 (0.54 to 1.03$)$ & 0.58 (0.42 to 0.81$)$ \\
\hline Nigeria & 2013 & 12175 & 0.62 (0.47 to 0.81$)$ & 0.49 (0.38 to 0.64$)$ \\
\hline Rwanda & 2014-2015 & 3127 & 0.50 (0.45 to 0.57$)$ & 0.50 (0.45 to 0.57$)$ \\
\hline Sierra Leone & 2013 & 4569 & 0.70 (0.56 to 0.87$)$ & 0.68 (0.56 to 0.84$)$ \\
\hline Zambia & 2014-2015 & 5013 & 0.58 (0.48 to 0.71$)$ & 0.56 (0.47 to 0.68$)$ \\
\hline Chad & 2014-2015 & 6493 & 0.32 (0.13 to 0.75$)$ & 0.35 (0.15 to 0.82$)$ \\
\hline Angola & 2015-2016 & 5738 & 0.52 (0.36 to 0.74$)$ & 0.47 (0.34 to 0.67$)$ \\
\hline Tanzania & 2015-2016 & 4153 & 0.29 (0.21 to 0.41$)$ & 0.24 (0.17 to 0.33$)$ \\
\hline Zimbabwe & 2015 & 2330 & $0.36(0.26$ to 0.51$)$ & 0.35 (0.25 to 0.49$)$ \\
\hline Malawi & 2015-2016 & 6561 & 0.66 (0.58 to 0.74$)$ & 0.67 (0.60 to 0.75$)$ \\
\hline Lesotho & 2014 & 1368 & 0.58 (0.45 to 0.75$)$ & 0.59 (0.46 to 0.76$)$ \\
\hline Kenya & 2014 & 3762 & 0.49 (0.38 to 0.61$)$ & 0.49 (0.39 to 0.61$)$ \\
\hline Uganda & 2016 & 5892 & 0.54 (0.46 to 0.63$)$ & 0.49 (0.42 to 0.57$)$ \\
\hline South Africa & 2016 & 1358 & 0.85 (0.75 to 0.96$)$ & 0.89 (0.78 to 1.00$)$ \\
\hline
\end{tabular}

*Adjusted for pregnancy planning, birth weight, region of residence, sex of child, mother's age at birth, mother's education, number of antenatal visits, birth order, maternal tobacco use, place of delivery, types of residence (rural/urban), distance to health facility, mother's occupation and household wealth.

Congo Bra, Congo-Brazzaville; Congo DR, Democratic Republic of the Congo; DHS, Demographic and Health Surveys; PR, prevalence ratio.

survey collection processes that enabled calculation of the breastfeeding indicators. Furthermore, to ensure contemporaneous analyses, only surveys with data collected from 2010 or later were included. The flow scheme for country selection is displayed in figure 1 .

A descriptive overview of the data is presented in table 1. The last three columns provide the prevalence of breastfeeding indicators while the third column provides the caesarean section rates among singleton last-born children who were born in the past 2 years before the survey. The proportion of live singleton births delivered by caesarean section ranged from $1.2 \%$ in Niger to $24.3 \%$ in South Africa. The prevalence of early initiation of breastfeeding was highest in Burundi (85.4\%) and lowest in Guinea at $16.4 \%$. The prevalence of exclusive breastfeeding under 6 months varied from $0.3 \%$ in Chad 


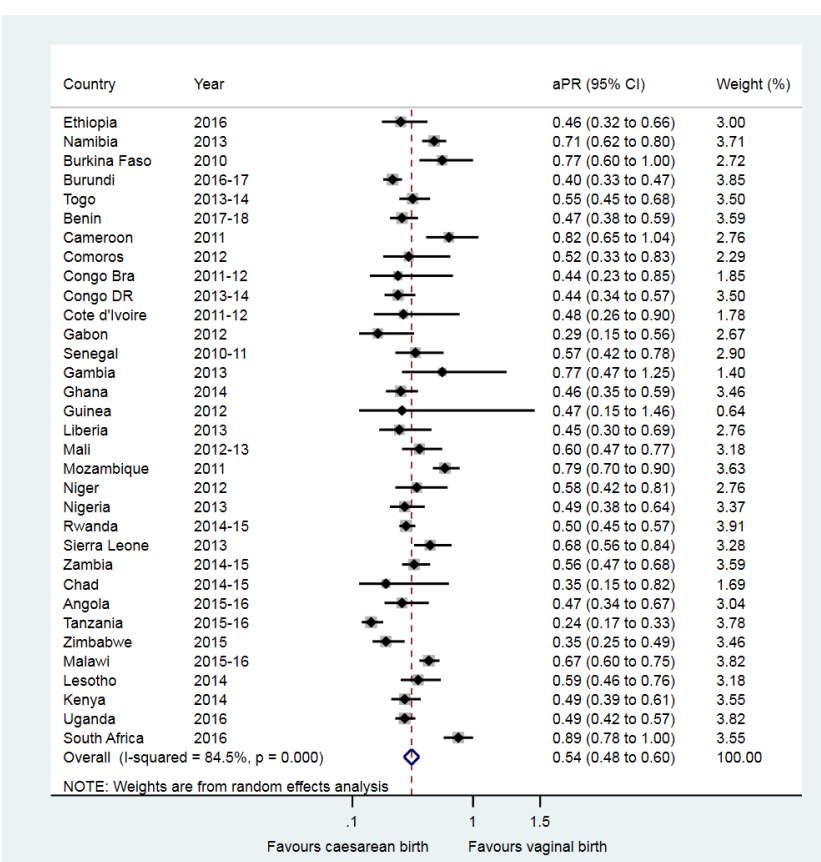

Figure 2 Association between caesarean birth and early initiation of breastfeeding in sub-Saharan Africa. aPR, adjusted prevalence ratio; Congo Bra, Congo-Brazzaville; Congo DR, Democratic Republic of the Congo.

to $88.0 \%$ in Rwanda. The prevalence of children ever breastfed is high across sub-Saharan African countries, with $97 \%$ of these countries have a prevalence of more than $90 \%$.

\section{Early initiation of breastfeeding}

At the individual country level, the fully adjusted analyses in table 2 show that, compared with vaginal birth, caesarean section was associated with aPR for early initiation of breastfeeding that ranged from 0.24 (95\% CI 0.17 to 0.33 ) in Tanzania to 0.89 (95\% CI 0.78 to 1.00 ) in South Africa. Figure 2 shows the random-effects meta-analysis where caesarean birth was associated with a $46.0 \%$ lower prevalence of early initiation of breastfeeding (pooled aPR, 0.54 (95\% CI 0.48 to 0.60 )). However, the heterogeneity associated with pooled estimates for early initiation of breastfeeding was high $\left(\chi^{2} p\right.$ value $=0.000, \mathrm{I}^{2}=84.5 \%$ ).

\section{Subgroup analyses}

Subgroup analyses were conducted to understand the possible source of heterogeneity associated with pooled estimate of the association between caesarean section and early initiation of breastfeeding based on geographic regions, rate of caesarean section and prevalence of early initiation of breastfeeding. These investigations did not indicate that any of these variables are important sources of heterogeneity (ie, the heterogeneity remains high). The forest plots from these subgroups investigation are presented in online web appendix 6, figures A-C.

\section{Exclusive breastfeeding under 6 months}

At the individual country level, the fully adjusted analyses in table 3 show that, compared with vaginal birth, caesarean section was associated with aPR for exclusive breastfeeding under 6 months that ranged from 0.58 (95\% CI 0.34 to 0.98 ) in Angola to a high aPR of 1.93 (95\% CI 0.46 to 8.10 ) in Cote d'Ivoire. Figure 3 shows the random-effects meta-analysis where caesarean birth was associated with a $6.0 \%$ lower prevalence of exclusive breastfeeding under 6 months (pooled aPR, 0.94 (95\% CI 0.88 to 1.01 )).

\section{Children ever breastfed}

At the individual country level, the fully adjusted analyses in table 4 show that, compared with vaginal birth, caesarean section was associated with aPR for children ever breastfed that ranged from 0.91 (95\% CI 0.82 to 1.02) in Gabon to 1.02 (95\% CI 0.98 to 1.06 ) in Guinea and 1.02 (95\% CI 0.99 to 1.04) in Gambia. Figure 4 shows the random-effects meta-analysis which indicated a $2 \%$ lower prevalence of children ever breastfed among caesarean versus vaginally born children (pooled aPR, 0.98 (95\% CI 0.98 to 0.99$)$ ).

\section{DISCUSSION \\ Main findings}

Our study examined the impact of caesarean section on breastfeeding indicators-early initiation of breastfeeding, exclusive breastfeeding under 6 months and children ever breastfed-in sub-Saharan Africa. The within-country aPR for early initiation of breastfeeding and exclusive breastfeeding under 6 months varies widely across countries but not for children ever breastfed. On the other hand, our finding in meta-analysis, combining the 33 countries data from sub-Saharan Africa shows that caesarean section had a negative influence on early initiation of breastfeeding (a $46 \%$ reduction in the prevalence of early initiation of breastfeeding). Our other meta-analyses showed little difference in exclusive breastfeeding under 6 months and children ever breastfed between infants born by caesarean section versus vaginal birth in sub-Saharan Africa.

Interventions such as physical and psychological support for women to initiate and establish successful breastfeeding after caesarean birth may be essential because early initiation of breastfeeding is linked to a greater success in establishing breastfeeding, helps the uterus to return to its normal size quickly, guarantees that the newborn receive 'colostrum' (the first breastmilk), avoids baby needing artificial feeds and reduces neonatal mortality. ${ }^{31-33}$

In this study, the rate of caesarean section in the past 2 years before the surveys ranged from 1.2\% in Niger to $24.3 \%$ in South Africa. This figure may reveal that caesarean section rate is low among some countries in sub-Saharan Africa which may be due to inadequate access, especially among the poorest women. ${ }^{34}$ The prevalence 
Table 3 Crude and multivariable-adjusted prevalence ratios for exclusive breastfeeding under 6 months associated with caesarean versus vaginal births

\begin{tabular}{|c|c|c|c|c|}
\hline Country & Year of DHS & Sample size & $\begin{array}{l}\text { Unadjusted PR } \\
(95 \% \mathrm{Cl})\end{array}$ & $\begin{array}{l}\text { Adjusted PR* } \\
(95 \% \mathrm{Cl})\end{array}$ \\
\hline Ethiopia & 2016 & 1081 & 0.87 (0.55 to 1.37$)$ & 0.80 (0.50 to 1.26$)$ \\
\hline Namibia & 2013 & 517 & 0.88 (0.66 to 1.19$)$ & 0.90 (0.66 to 1.22 ) \\
\hline Burkina Faso & 2010 & 1433 & 1.01 (0.48 to 2.14$)$ & 0.95 (0.46 to 1.95$)$ \\
\hline Burundi & 2016-2017 & 1213 & 0.95 (0.84 to 1.08$)$ & 0.97 (0.86 to 1.09$)$ \\
\hline Togo & 2013-2014 & 589 & 1.24 (0.99 to 1.55$)$ & 1.10 (0.88 to 1.38$)$ \\
\hline Benin & 2017-2018 & 1339 & 0.99 (0.69 to 1.42$)$ & 1.01 (0.73 to 1.39 ) \\
\hline Cameroon & 2011 & 1094 & 2.18 (1.37 to 3.47$)$ & 1.64 (1.06 to 2.52 ) \\
\hline Comoros & 2012 & 318 & $1.13(0.40$ to 3.19$)$ & 1.29 (0.49 to 3.35$)$ \\
\hline Congo Bra & 2011-2012 & 934 & 0.78 (0.34 to 1.80$)$ & 1.02 (0.38 to 2.78$)$ \\
\hline Congo DR & 2013-2014 & 1895 & 0.88 (0.60 to 1.29$)$ & 0.75 (0.51 to 1.11$)$ \\
\hline Cote d'Ivoire & 2011-2012 & 760 & 2.51 (1.03 to 6.09$)$ & 1.93 (0.46 to 8.10$)$ \\
\hline Gabon & 2012 & 621 & 1.05 (0.20 to 5.55$)$ & 1.10 (0.15 to 8.05$)$ \\
\hline Senegal & 2010-2011 & 1308 & 1.18 (0.79 to 1.78$)$ & 1.14 (0.75 to 1.71$)$ \\
\hline Gambia & 2013 & 939 & 0.80 (0.37 to 1.72$)$ & 0.84 (0.39 to 1.79$)$ \\
\hline Ghana & 2014 & 598 & 0.98 (0.72 to 1.32$)$ & 1.01 (0.74 to 1.37 ) \\
\hline Guinea & 2012 & 701 & $0.98(0.23$ to 4.13$)$ & 0.67 (0.19 to 2.45$)$ \\
\hline Liberia & 2013 & 708 & 1.36 (1.01 to 1.84$)$ & 1.46 (1.09 to 1.97$)$ \\
\hline Mali & 2012-2013 & 984 & 1.51 (1.01 to 2.25$)$ & 1.53 (1.02 to 2.31$)$ \\
\hline Mozambique & 2011 & 1025 & 0.91 (0.57 to 1.45$)$ & 0.84 (0.54 to 1.30$)$ \\
\hline Niger & 2012 & 1281 & 0.83 (0.30 to 2.24$)$ & 0.69 (0.24 to 1.92$)$ \\
\hline Nigeria & 2013 & 2881 & 1.69 (1.02 to 2.82$)$ & 0.77 (0.48 to 1.26$)$ \\
\hline Rwanda & 2014-2015 & 690 & 0.91 (0.81 to 1.01 ) & 0.92 (0.82 to 1.02$)$ \\
\hline Sierra Leone & 2013 & 1095 & 1.11 (0.68 to 1.82$)$ & 1.30 (0.85 to 1.99$)$ \\
\hline Zambia & 2014-2015 & 1170 & 0.84 (0.65 to 1.09$)$ & 0.89 (0.68 to 1.17$)$ \\
\hline Angola & 2015-2016 & 1588 & 0.65 (0.36 to 1.18$)$ & 0.58 (0.34 to 0.98$)$ \\
\hline Tanzania & 2015-2016 & 997 & 0.80 (0.58 to 1.09$)$ & 0.76 (0.55 to 1.07$)$ \\
\hline Zimbabwe & 2015 & 590 & 0.95 (0.61 to 1.47 ) & 1.09 (0.73 to 1.64$)$ \\
\hline Malawi & 2015-2016 & 1605 & 1.20 (1.03 to 1.39$)$ & 1.16 (0.99 to 1.37$)$ \\
\hline Lesotho & 2014 & 322 & 0.96 (0.68 to 1.34$)$ & 1.10 (0.85 to 1.44$)$ \\
\hline Kenya & 2014 & 845 & 0.79 (0.55 to 1.13$)$ & 0.73 (0.53 to 1.00$)$ \\
\hline Uganda & 2016 & 1459 & 0.91 (0.75 to 1.10$)$ & 0.90 (0.75 to 1.09$)$ \\
\hline South Africa & 2016 & 339 & 0.69 (0.42 to 1.13$)$ & 0.76 (0.49 to 1.19$)$ \\
\hline
\end{tabular}

*Adjusted for pregnancy planning, birth weight, region of residence, sex of child, mother's age at birth, mother's education, number of antenatal visits, birth order, maternal tobacco use, place of delivery, types of residence (rural/urban), distance to health facility, mother's occupation and household wealth.

Congo Bra, Congo-Brazzaville; Congo DR, Democratic republic of the Congo; DHS, Demographic and Health Surveys; PR, prevalence ratio.

of early initiation of breastfeeding ranged from $16.4 \%$ to 85.4\% across the 33 sub-Saharan African countries with one-third of these countries have a prevalence of less than $50 \%$, suggesting a considerable proportion of newborns are not breastfed within 1 hour postbirth. Similarly, there were a substantial disparities in the prevalence of exclusive breastfeeding under 6 months in sub-Saharan Africa (ranged from $0.3 \%$ to $88.0 \%$ ), with a very low prevalence in Chad $(0.3 \%)$ and Gabon $(6.1 \%)$. The very low prevalence of exclusive breastfeeding under 6 months in Chad and Gabon may warrant the need for urgent interventions such as improving counselling skills of health workers on exclusive breastfeeding and increasing the family and/or community support for breastfeeding ${ }^{35}$ in these countries. However, the prevalence of children ever breastfed is high (90\% plus) among the majorities of countries (ie, 32 countries) and ranged from $84.4 \%$ in South Africa to $99.2 \%$ in Burkina Faso. 


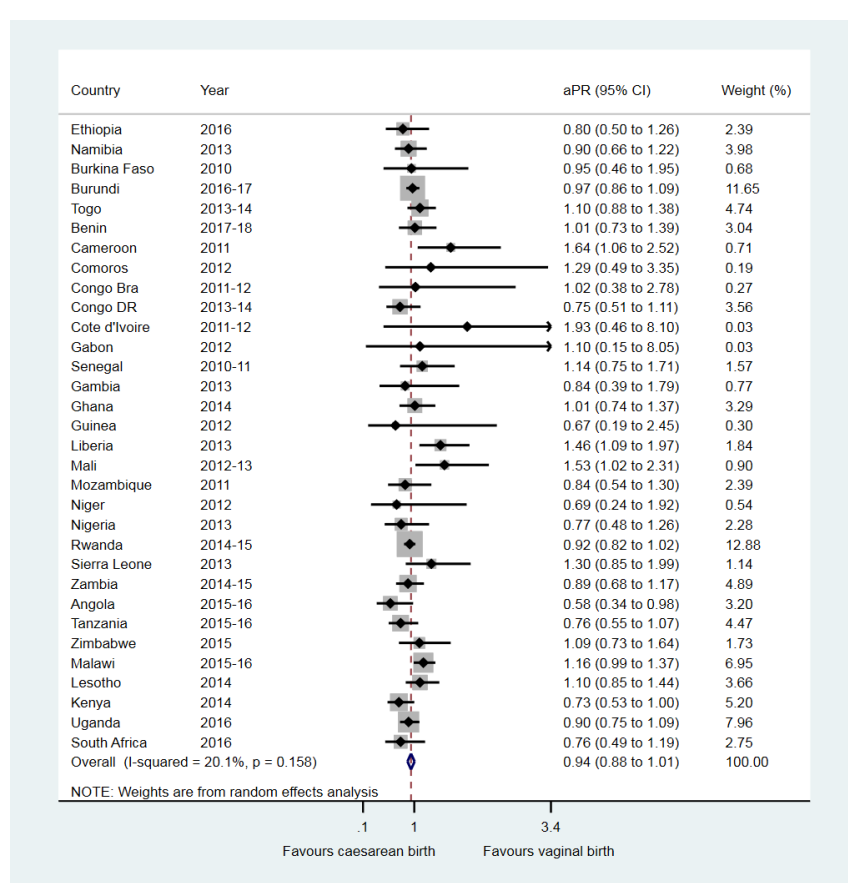

Figure 3 Association between caesarean birth and exclusive breastfeeding under 6 months in sub-Saharan Africa. aPR, adjusted prevalence ratio; Congo Bra, CongoBrazzaville; Congo DR, Democratic Republic of the Congo.

\section{Early initiation of breastfeeding}

Our within-country adjusted analyses and random-effects meta-analysis of 33 countries revealed that the prevalence of early initiation of breastfeeding was lower among infants delivered by caesarean section compared with infants born vaginally. This finding is consistent with a previous study conducted in Canada that reported more women who underwent planned caesarean birth did not initiate breastfeeding. ${ }^{19}$ Moreover, Takahashi et $a l^{6}$ in their study conducted based on WHO global surveys completed in 24 countries in Africa, Latin America and Asia found that caesarean delivery was negatively associated with the rate of early initiation of breastfeeding. It has been suggested that early initiation of breastfeeding has numerous benefits for newborns. For example, early initiation of breastfeeding, which can be supported and facilitated by skin-to-skin contact between mother and infant, may promote exclusive breastfeeding under 6 months of life. Findings from our meta-analysis which showed a $46 \%$ reduction in the practice of early initiation of breastfeeding among infants born by caesarean versus vaginal births is of public health importance, and health programmes and healthcare providers in low-income and middle-income countries should consider interventions to promote and support early initiation of breastfeeding.

Support to improve early initiation of breastfeeding should be a priority to improve neonatal survival and enhance long-term health of infants. Not initiating breastfeeding within an hour is associated with an increased risks of neonatal mortality and reduced opportunity of benefiting from the immune properties that the 'colostrum' provides to the newborns. ${ }^{32} 33$

An earlier meta-analysis that included studies conducted outside of Africa ${ }^{20}$ reported a similar result to ours: the negative effect of caesarean section on early initiation of breastfeeding is more pronounced among children born after caesarean section than after vaginal birth. Interventions such as immediate or early skin-to-skin contact, parent education and use of hand expressed breastmilk (to establish and maintain an adequate milk supply) may help mothers to practice early initiation of breastfeeding following caesarean birth in sub-Saharan Africa.

\section{Exclusive breastfeeding under 6 months and children ever breastfed}

The present study showed that the within-country aPR for exclusive breastfeeding under 6 months associated with caesarean versus vaginally born infants varied from a low aPR of 0.58 (95\% CI 0.34 to 0.98) in Angola to a high aPR of 1.93 (95\% CI 0.46 to 8.10) in Cote d'Ivoire. These findings suggest that caesarean section favours the practice of exclusive breastfeeding under 6 months for some countries, while it has adverse effects for others. These associations would appear to be counter-intuitive, given that caesarean section may be a barrier for exclusive breastfeeding under 6 months, yet given that institutional delivery, where the procedure is performed, caesarean section is among the facilitators of exclusive breastfeeding. ${ }^{37}$ In developing countries, most poor women give birth at home assisted by traditional birth attendants. Cultural beliefs and traditional feeding practices may prevent women from initiating breastfeeding immediately postbirth, which, in turn, affects the practice of exclusive breastfeeding under 6 months. ${ }^{238}$ Therefore, when poor and/or uneducated women undergo caesarean section in developing countries, there is a possibility that women fed their newborn exclusively breast milk because health workers provide immediate breastfeeding support at delivery in health facilities. This was confirmed by a previous study which reported interventions such as individual immediate breastfeeding support at delivery, counselling or group education and lactation management increase exclusive breastfeeding by $49 \%$ (95\% CI 33 to 68 ) and any breastfeeding by $66 \%$ (95\% CI 34 to 107). ${ }^{39}$

On the other hand, the findings of our meta-analysis suggested little influence in exclusive breastfeeding under 6 months (pooled aPR, 0.94 (95\% CI 0.88 to 1.01) and children ever breastfed (pooled aPR, $0.98 \quad(95 \%$ CI 0.98 to 0.99 ) among caesarean versus vaginally born infants in sub-Saharan Africa. The current findings are comparable with two previous studies which found that caesarean section has little influence on exclusive breastfeeding (risk ratio, $1.08 ; 95 \%$ CI 0.82 to 1.41$)^{39}$ and any breastfeeding practice at 6 months among mothers who initiated breastfeeding (pooled OR, 0.95; 95\% CI 0.89 to $1.01) .^{20}$ 
Table 4 Crude and multivariable-adjusted prevalence ratios for children ever breastfed, associated with caesarean versus vaginal births

\begin{tabular}{|c|c|c|c|c|}
\hline Country & Year of DHS & Sample size & $\begin{array}{l}\text { Unadjusted PR } \\
(95 \% \mathrm{Cl})\end{array}$ & $\begin{array}{l}\text { Adjusted PR* } \\
(95 \% \mathrm{CI})\end{array}$ \\
\hline Ethiopia & 2016 & 4021 & 0.93 (0.84 to 1.04$)$ & 0.93 (0.84 to 1.04 \\
\hline Namibia & 2013 & 2021 & 0.99 (0.96 to 1.03$)$ & 1.00 (0.96 to 1.03 \\
\hline Burkina Faso & 2010 & 5745 & 0.98 (0.94 to 1.01$)$ & 0.98 (0.94 to 1.02 \\
\hline Burundi & $2016-2017$ & 5182 & 0.98 (0.96 to 1.01$)$ & $0.98(0.96$ to 1.01 \\
\hline Togo & 2013-2014 & 2707 & 0.97 (0.94 to 1.00$)$ & 0.97 (0.94 to 1.01 \\
\hline Benin & 2017-2018 & 5337 & 0.99 (0.96 to 1.02 ) & 0.99 (0.97 to 1.02 \\
\hline Cameroon & 2011 & 4604 & 0.98 (0.95 to 1.01$)$ & $1.00(0.96$ to 1.03 \\
\hline Comoros & 2012 & 1228 & 0.97 (0.91 to 1.04$)$ & 0.98 (0.92 to 1.04 \\
\hline Congo Bra & 2011-2012 & 3754 & 0.93 (0.86 to 1.01$)$ & 0.94 (0.87 to 1.02 \\
\hline Congo DR & 2013-2014 & 7189 & 0.98 (0.96 to 1.00$)$ & 0.98 (0.96 to 1.01 \\
\hline Cote d'Ivoire & 2011-2012 & 3037 & 0.97 (0.91 to 1.04$)$ & 0.99 (0.93 to 1.06 \\
\hline Gabon & 2012 & 2452 & 0.90 (0.80 to 1.02$)$ & 0.91 (0.82 to 1.02 \\
\hline Senegal & 2010-2011 & 4809 & 0.95 (0.91 to 1.00$)$ & 0.95 (0.91 to 1.00 \\
\hline Gambia & 2013 & 3429 & 1.00 (0.98 to 1.02$)$ & 1.02 (0.99 to 1.04 \\
\hline Ghana & 2014 & 2281 & 0.97 (0.94 to 1.00$)$ & 0.97 (0.94 to 1.01 \\
\hline Guinea & 2012 & 2748 & 1.00 (0.97 to 1.03$)$ & 1.02 (0.98 to 1.06 \\
\hline Liberia & 2013 & 3001 & 0.95 (0.88 to 1.02 ) & 0.94 (0.88 to 1.01 \\
\hline Mali & 2012-2013 & 3884 & 1.00 (0.98 to 1.03$)$ & 1.01 (0.98 to 1.03 \\
\hline Mozambique & 2011 & 4519 & 1.00 (0.98 to 1.02$)$ & 1.01 (0.99 to 1.04 \\
\hline Niger & 2012 & 4668 & 0.96 (0.89 to 1.04$)$ & 0.97 (0.89 to 1.05 \\
\hline Nigeria & 2013 & 12175 & 0.93 (0.89 to 0.97 ) & 0.93 (0.89 to 0.98 \\
\hline Rwanda & 2014-2015 & 3127 & 0.98 (0.97 to 1.00$)$ & 0.99 (0.97 to 1.00 \\
\hline Sierra Leone & 2013 & 4569 & 0.94 (0.88 to 0.99$)$ & 0.93 (0.89 to 0.99 \\
\hline Zambia & 2014-2015 & 5013 & 0.98 (0.95 to 1.01$)$ & 1.00 (0.96 to 1.03 \\
\hline Chad & 2014-2015 & 6493 & 0.95 (0.89 to 1.01$)$ & 0.96 (0.90 to 1.03 \\
\hline Angola & 2015-2016 & 5738 & 0.99 (0.94 to 1.05$)$ & 0.97 (0.92 to 1.02 \\
\hline Tanzania & 2015-2016 & 4153 & 0.97 (0.94 to 1.00$)$ & 0.96 (0.93 to 1.00 \\
\hline Zimbabwe & 2015 & 2330 & 0.98 (0.95 to 1.01$)$ & 0.98 (0.95 to 1.01 \\
\hline Malawi & 2015-2016 & 6561 & 0.99 (0.96 to 1.01$)$ & 0.98 (0.96 to 1.01 \\
\hline Lesotho & 2014 & 1368 & 0.96 (0.88 to 1.04$)$ & 0.98 (0.92 to 1.04 \\
\hline Kenya & 2014 & 3762 & 1.01 (1.00 to 1.02 ) & 1.01 (1.00 to 1.02 \\
\hline Uganda & 2016 & 5892 & 0.98 (0.96 to 1.00$)$ & 0.98 (0.96 to 1.00 \\
\hline South Africa & 2016 & 1358 & 0.93 (0.86 to 1.00$)$ & 0.96 (0.89 to 1.03 \\
\hline
\end{tabular}

*Adjusted for pregnancy planning, birth weight, region of residence, sex of child, mother's age at birth, mother's education, number of antenatal visits, birth order, maternal tobacco use, place of delivery, types of residence (rural/urban), distance to health facility, mother's occupation and household wealth.

Congo Bra, Congo-Brazzaville; Congo DR, Democratic Republic of the Congo; DHS, Demographic and Health Surveys; PR, prevalence ratio.

\section{Strengths and limitations of this study}

The strength of the present study include the use of nationally representative data on a large number of countries ( $\mathrm{n}=33$ countries) over a long time period (2010$2017 / 2018$ ). As the small number of previous studies on caesarean section and breastfeeding are from countries outside the African continent, the present study provides insight into the link between caesarean section and breastfeeding in low-income and middle-income countries in
sub-Saharan Africa. This is important because caesarean section rate is increasing in low-income and middle-income countries, and early initiation of breastfeeding may be compromised when mothers undergo caesarean section due to several factors such as mothers' emotional health and restricted mobility in the early days after the surgery. Moreover, in addition to the within-country adjusted analyses of nationally representative surveys data, we have also summarised our findings in a meta-analysis, 


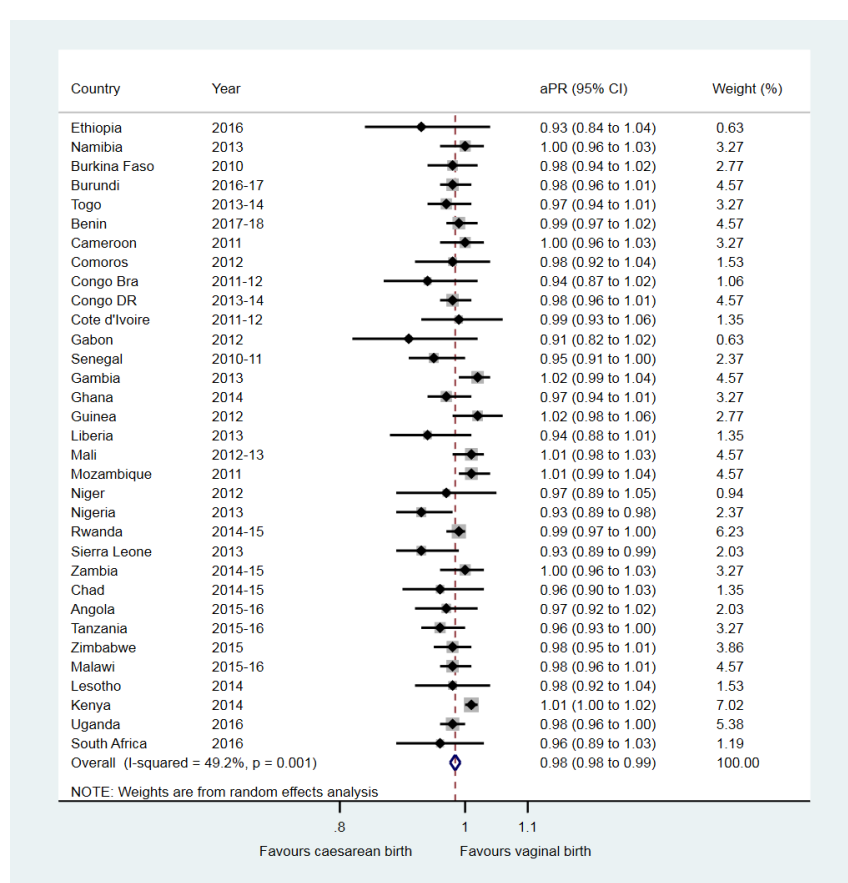

Figure 4 Association between caesarean birth and children ever breastfed in sub-Saharan Africa. aPR, adjusted prevalence ratio; Congo Bra, Congo-Brazzaville; Congo DR, Democratic Republic of the Congo.

combining data analysed individually to provide a consolidated effect estimate of the impact of caesarean section on breastfeeding indicators in sub-Saharan Africa.

We acknowledge the following limitations of this study. First, despite the high-quality of DHS data in low-income and middle-income countries, the ascertainment of breastfeeding practice depends on retrospective maternal reports, which is at risk of misreporting. Nevertheless, a study in Mexico ${ }^{40}$ showed that the reliability of retrospective maternal reports of any breastfeeding practice was high (intraclass correlation coefficient $=0.94$ ). Furthermore, a review of 10 studies from developed and developing countries suggested a less than 3-year maternal recall period of any breastfeeding and breastfeeding duration is valid and reliable but did not include any study specifically assessing early initiation of breastfeeding. ${ }^{41}$ On the other hand, the proportion of children exclusively breastfed may be overestimated because exclusive breastfeeding under 6 months is ascertained based on 'previous day recall period', and some children who are given other liquids irregularly may not have received other liquids or solid foods before the survey day. ${ }^{11} \mathrm{~A}$ study from South Africa also revealed that maternal recall of exclusive breastfeeding is limited in accuracy when compared with the 'objective stable isotope method' for assessing exclusive breastfeeding. ${ }^{42}$ Furthermore, DHS in developing countries are prone to incomplete and inconsistent reporting. Nonetheless, to overcome this problem, the DHS Program performs extensive data editing, including imputation of incomplete dates ${ }^{43}$ and make the final edited data files accessible to data users worldwide.
Second, DHS data do not distinguish whether the caesarean section was medically indicated or not. This would be useful to study in the future as it would be important to know whether delayed initiation of breastfeeding occurs in non-medically indicated caesarean birth, as this could be addressed in institutional settings. It may be more challenging to address delayed initiation of breastfeeding among medically indicated emergency caesarean section if mothers or neonates are too sick to commence breastfeeding. However, mothers should be supported to start early expression of breast milk to establish and maintain an adequate milk supply when the newborn is too ill to breastfeed, or if the obstetric complication prevents mother from breastfeeding directly. Third, as DHS lack data on income and expenditures to measure socioeconomic position (SEP) of the household, we have used wealth index as measure of relative SEP of the household. While previous studies suggests that asset-based index is resistant to most economic shocks and is less variable in response to income and expenditure fluctuations, the wealth index can be considered to be a more stable measure of SEP than consumption expenditure in low-income and middle-income countries. ${ }^{44} 45$

Finally, heterogeneity associated with pooled estimates for 'early initiation of breastfeeding' among caesarean versus vaginally born infants is high and the source/s of heterogeneity remain unclear after subgroups analyses performed to explore why the effect estimates differ. Although we cannot be sure about the source of heterogeneity, the clinical presentation of mothers and newborn during the perinatal period may be considered as one possible source. For example, for women who delivered by emergency caesarean section after severe obstetric complication, initiation of breastfeeding with an hour may be very difficult or impossible, while for women with less labour complication delivered by emergency caesarean section or planned caesarean section, initiation of breastfeeding within 1 hour after birth may be a possibility. These scenarios may suggest clinical heterogeneity between the analyses performed in each country because of the clinical difference (eg, due to confounding by indication) between countries data analysed. It has previously been suggested that clinical heterogeneity (ie, clinical deference between studies or trials) should be explored. ${ }^{46}$

\section{CONCLUSIONS}

Caesarean section had a negative influence on early initiation of breastfeeding but showed little association with exclusive breastfeeding under 6 months and children ever breastfed among infants born after caesarean section versus vaginal birth in sub-Saharan Africa. Health interventions to promote and support women to initiate and maintain breastfeeding after caesarean birth should be considered. 
Author affiliations

${ }^{1}$ School of Public Health, The University of Adelaide, Adelaide, South Australia, Australia

${ }^{2}$ School of Allied Health Sciences, College of Health Sciences, Addis Ababa University, Addis Ababa, Ethiopia

${ }^{3}$ Robinson Research Institute, School of Medicine, The University of Adelaide, Adelaide, South Australia, Australia

${ }^{4}$ Department of Obstetrics and Gynaecology, Monash University, Melbourne, Victoria, Australia

${ }^{5}$ Population Health Sciences, University of Bristol, England, UK

Acknowledgements The authors are grateful to The DHS Program for providing the data sets used for this analysis. BWM is supported by an NHMRC Practitioner Fellowship (GNT1082548) and also reports consultancy for ObsEva, Merck Merck $\mathrm{KGaA}$, and Guerbet. JWL is supported by an NHMRC Centre of Research Excellence (GNT1099422).

Contributors All authors contributed to the design of the study and the interpretation of data. EY performed the data analysis and drafted the manuscript. All other authors critically revised the draft manuscript. All authors read and approved the final manuscript. EY is the guarantor of the paper.

Funding The first author is fully supported by an Australian Government Research Training Programme (RTP) Scholarship.

Competing interests None declared.

Patient consent for publication Not required.

Provenance and peer review Not commissioned; externally peer reviewed.

Data availability statement Data are available in a public, open access repository.

Open access This is an open access article distributed in accordance with the Creative Commons Attribution Non Commercial (CC BY-NC 4.0) license, which permits others to distribute, remix, adapt, build upon this work non-commercially, and license their derivative works on different terms, provided the original work is properly cited, appropriate credit is given, any changes made indicated, and the use is non-commercial. See: http://creativecommons.org/licenses/by-nc/4.0/.

\section{REFERENCES}

1. Victora CG, Bahl R, Barros AJD, et al. Breastfeeding in the 21st century: epidemiology, mechanisms, and lifelong effect. The Lancet 2016;387:475-90.

2. Sharma IK, Byrne A. Early initiation of breastfeeding: a systematic literature review of factors and barriers in South Asia. Int Breastfeed $J$ 2016;11:17

3. Bowatte G, Tham R, Allen KJ, et al. Breastfeeding and childhood acute otitis media: a systematic review and meta-analysis. Acta Paediatr 2015;104:85-95.

4. Giugliani ERJ, Horta BL, Loret de Mola C, et al. Effect of breastfeeding promotion interventions on child growth: a systematic review and meta-analysis. Acta Paediatr 2015;104:20-9.

5. Horta BL, Victora CG, World Health Organization. Short-Term effects of breastfeeding: a systematic review on the benefits of breastfeeding on diarrhoea and pneumonia mortality, 2013. Available: http://www.who.int/iris/handle/10665/95585

6. Lodge CJ, Tan DJ, Lau MXZ, et al. Breastfeeding and asthma and allergies: a systematic review and meta-analysis. Acta Paediatr 2015;104:38-53.

7. Ip S, Chung M, Raman G, et al. A summary of the agency for healthcare research and quality's evidence report on breastfeeding in developed countries. Breastfeed Med 2009;4(Suppl 1):S17-30.

8. Aune D, Norat T, Romundstad P, et al. Breastfeeding and the maternal risk of type 2 diabetes: a systematic review and doseresponse meta-analysis of cohort studies. Nutr Metab Cardiovasc Dis 2014;24:107-15.

9. Chowdhury R, Sinha B, Sankar MJ, et al. Breastfeeding and maternal health outcomes: a systematic review and meta-analysis. Acta Paediatr 2015;104:96-113.

10. World Health Organization. Guideline: protecting, promoting and supporting breastfeeding in facilities providing maternity and newborn services. Geneva: World Health Organization, 2017.

11. WHO, UNICEF, USAID, AED, UCDAVIS, IFPRI. Indicators for assessing infant and young child feeding practices, Part I: Definitions. Conclusions of a consensus meeting held 6-8 November 2007. Washington D.C, USA. Geneva: World Health Organization,
2008. https://www.who.int/nutrition/publications/infantfeeding/ 9789241596664/en/

12. Tully KP, Ball HL. Postnatal unit bassinet types when rooming-in after cesarean birth: implications for breastfeeding and infant safety. $J$ Hum Lact 2012;28:495-505.

13. Tully KP, Ball HL. Maternal accounts of their breast-feeding intent and early challenges after caesarean childbirth. Midwifery 2014;30:712-9.

14. Karlström A, Engström-Olofsson R, Norbergh K-G, et al. Postoperative pain after cesarean birth affects breastfeeding and infant care. J Obstet Gynecol Neonatal Nurs 2007;36:430-40.

15. Kolås T, Saugstad OD, Daltveit AK, et al. Planned cesarean versus planned vaginal delivery at term: Comparison of newborn infant outcomes. Am J Obstet Gynecol 2006;195:1538-43.

16. Zanardo V, Svegliado G, Cavallin F, et al. Elective cesarean delivery: does it have a negative effect on breastfeeding? Birth 2010;37:275-9.

17. Evans KC, Evans RG, Royal R, et al. Effect of caesarean section on breast milk transfer to the normal term newborn over the first week of life. Arch Dis Child Fetal Neonatal Ed 2003;88:380F-2.

18. Hyde MJ, Mostyn A, Modi N, et al. The health implications of birth by caesarean section. Biological Reviews 2012;87:229-43.

19. Hobbs AJ, Mannion CA, McDonald SW, et al. The impact of caesarean section on breastfeeding initiation, duration and difficulties in the first four months postpartum. BMC Pregnancy Childbirth 2016;16:90.

20. Prior E, Santhakumaran S, Gale C, et al. Breastfeeding after cesarean delivery: a systematic review and meta-analysis of world literature. Am J Clin Nutr 2012;95:1113-35.

21. Boatin AA, Schlotheuber A, Betran AP, et al. Within country inequalities in caesarean section rates: observational study of 72 low and middle income countries. BMJ 2018;360.

22. Ologunde R, Vogel JP, Cherian MN, et al. Assessment of cesarean delivery availability in 26 low- and middle-income countries: a crosssectional study. Am J Obstet Gynecol 2014;211:504.e1-12.

23. Say L, Raine R. A systematic review of inequalities in the use of maternal health care in developing countries: examining the scale of the problem and the importance of context. Bull World Health Organ 2007:85:812-9.

24. Holmer H, Lantz A, Kunjumen T, et al. Global distribution of surgeons, anaesthesiologists, and obstetricians. Lancet Glob Health 2015;3(Suppl 2):S9-11.

25. Stanton CK, Dubourg D, De Brouwere V, et al. Reliability of data on caesarean sections in developing countries. Bull World Health Organ 2005;83:449-55.

26. Filmer D, Pritchett LH. Estimating wealth effects without expenditure data--or tears: an application to educational enrollments in states of India. Demography 2001;38:115-32.

27. Filmer D, Scott K. Assessing asset indices. Demography 2012;49:359-92.

28. Cummings P. Methods for estimating adjusted risk ratios. Stata $J$ 2009:9:175-96.

29. Zou G. A modified poisson regression approach to prospective studies with binary data. Am J Epidemiol 2004;159:702-6.

30. Kyu HH, Shannon HS, Georgiades K, et al. Caesarean delivery and neonatal mortality rates in 46 low- and middle-income countries: a propensity-score matching and meta-analysis of demographic and health survey data. Int J Epidemiol 2013;42:781-91.

31. Ballard O, Morrow AL. Human milk composition: nutrients and bioactive factors. Pediatr Clin North Am 2013;60:49-74.

32. Smith ER, Hurt L, Chowdhury R, et al. Delayed breastfeeding initiation and infant survival: a systematic review and meta-analysis. PLoS One 2017;12:e0180722.

33. Edmond KM, Zandoh C, Quigley MA, et al. Delayed breastfeeding initiation increases risk of neonatal mortality. Pediatrics 2006;117:e380-6.

34. Boerma T, Ronsmans C, Melesse DY, et al. Global epidemiology of use of and disparities in caesarean sections. The Lancet 2018;392:1341-8.

35. Kavle JA, LaCroix E, Dau $\mathrm{H}$, et al. Addressing barriers to exclusive breast-feeding in low- and middle-income countries: a systematic review and programmatic implications. Public Health Nutr 2017;20:3120-34.

36. Takahashi K, Ganchimeg T, Ota E, et al. Prevalence of early initiation of breastfeeding and determinants of delayed initiation of breastfeeding: secondary analysis of the WHO Global Survey. Sci Rep 2017;7:44868.

37. Balogun OO, Dagvadorj A, Anigo KM, et al. Factors influencing breastfeeding exclusivity during the first 6 months of life in developing countries: a quantitative and qualitative systematic review. Matern Child Nutr 2015;11:433-51. 
38. Montagu D, Yamey G, Visconti A, et al. Where do poor women in developing countries give birth? A Multi-Country analysis of demographic and health survey data. PLOS One 2011;6:e17155.

39. Rollins NC, Bhandari N, Hajeebhoy N, et al. Why invest, and what it will take to improve breastfeeding practices? The Lancet 2016;387:491-504.

40. Cupul-Uicab LA, Gladen BC, Hernández-Ávila M, et al. Reliability of reported breastfeeding duration among reproductive-aged women from Mexico. Matern Child Nutr 2009;5:125-37.

41. Li R, Scanlon KS, Serdula MK. The validity and reliability of maternal recall of breastfeeding practice. Nutr Rev 2005;63:103-10.

42. Mulol $\mathrm{H}$, Coutsoudis A. Limitations of maternal recall for measuring exclusive breastfeeding rates in South African mothers. Int Breastfeed J 2018;13:19.
43. Croft T. "Date Editing and Imputation". In Demographic and Health Surveys World Conference Proceedings, II: 1337-1356, Columbia, Maryland: IRD/ORC Macro., 1991. Available: https://dhsprogram. com/publications/publication-DHSG3-DHS-Questionnaires-andManuals.cfm

44. Howe LD, Galobardes B, Matijasevich A, et al. Measuring socioeconomic position for epidemiological studies in low- and middleincome countries: a methods of measurement in epidemiology paper. Int J Epidemiol 2012;41:871-86.

45. Liverpool-Tasie LSO, Winter-Nelson A. Asset versus consumption poverty and poverty dynamics in rural Ethiopia. Agricultural Economics 2011;42:221-33.

46. Thompson SG. Systematic review: why sources of heterogeneity in meta-analysis should be investigated. BMJ 1994;309:1351-5. 